\title{
Modern proposal of methodology for retrieval of characteristic synthetic rainfall hyetographs
}

\author{
Paweł Licznar ${ }^{1, *}$, Ewa Burszta-Adamiak ${ }^{2}$, Janusz Łomotowski², and Justyna Stańczyk ${ }^{2}$ \\ ${ }^{1}$ Wroclaw University of Science and Technology, Faculty of Environmental Engineering, Wybrzeze \\ Wyspianskiego 27, 50-370 Wroclaw, Poland \\ ${ }^{2}$ Wroclaw University of Environmental and Life Sciences, Institute of Environmental Engineering, \\ pl. Grunwaldzki 24, 50-363 Wroclaw, Poland
}

\begin{abstract}
Modern engineering workshop of designing and modelling complex drainage systems is based on hydrodynamic modelling and has a probabilistic character. Its practical application requires a change regarding rainfall models accepted at the input. Previously used artificial rainfall models of simplified form, e.g. block precipitation or Euler's type II model rainfall are no longer sufficient. It is noticeable that urgent clarification is needed as regards the methodology of standardized rainfall hyetographs that would take into consideration the specifics of local storm rainfall temporal dynamics. The aim of the paper is to present a proposal for innovative methodology for determining standardized rainfall hyetographs, based on statistical processing of the collection of actual local precipitation characteristics. Proposed methodology is based on the classification of standardized rainfall hyetographs with the use of cluster analysis. Its application is presented on the example of selected rain gauges localized in Poland. Synthetic rainfall hyetographs achieved as a final result may be used for hydrodynamic modelling of sewerage systems, including probabilistic detection of necessary capacity of retention reservoirs.
\end{abstract}

\section{Introduction}

Computerized hydrodynamic models enable to conduct complex hydraulic analyses of even very complicated drainage networks. The aim of these analyses is often to recognize not only storm water runoff through the network of underground sewers, but also e.g. rainwater surface runoff or water retention within the system [1-5]. The application of such computerized hydrodynamic models of storm sewer systems places entirely new demands as regards input precipitation data. In practice, when it is not possible to feed the model with uninterrupted precipitation time series at high resolution, standardized rainfall hyetographs are used. They are designed on the basis of empirical formulae of design rainfall intensities (IDF type curves - Intensity-Duration-Frequency) [6, 7]. Today one of

\footnotetext{
* Corresponding author: pawel.licznar@pwr.edu.pl
} 
the most popular standardized hyetographs is Euler's type II. This model, recommended for simulating dynamic sewage, is also used in Poland due to the lack of reliable equivalents. Euler's type II is relatively easy to design, however its application raises numerous doubts $[8,9]$. The alternative to using model (standardized) rainfall may be generating synthetic rainfall time series with the use of random generators. For example, Güntner et.al [10] and Licznar et al. [11] showed multifractal properties of rainfall registered by selected rain gauges and prepared multiplicative random cascade models generating synthetic rainfall time series at high time resolution. Nevertheless, due to advanced scientific sources needed do design random cascade models, practical application of synthetic rainfall time series in hydrodynamic modelling of sewerage systems, e.g. in order to perform probabilistic calculation of retention reservoirs necessary capacity, remains infrequent. [5].

The analyses of precipitation temporal changes towards developing reliable model patterns have attracted numerous researchers from various parts of the world. One of the most recent announcements in this area is a paper by Hassan El-Sayed [12] in which synthetic rainfall hyetographs (WRRI) were presented, and categorized into four groups depending on rainfall total duration $(6 \mathrm{hr}, 12 \mathrm{hr}, 18 \mathrm{hr}, 24 \mathrm{hr}$ ). They were compared to the standard Soil Conservation Service (SCS) distributions of type I, II, III and IA. Significant differences were shown in runoff computed on the basis of the hyetographs and the abovementioned SCS models. It indicates the need to reject simplified global standardized rainfall models and the necessity to find their local equivalents. Unfortunately, research in this area is still not common in Poland. Only analyses within one city - Warsaw - may be listed, conducted by Barszcz [13] and Licznar and Szeląg [9]. Also not since long there have been reports in literature about research on real urban catchments in Poland, which verify the accuracy of synthetic rainfall time series, based on local rainfall models [5, 14].

Having in mind the depicted state of knowledge and needs as regards feeding hydrodynamic models with rainfall data, it seems necessary to intensify the work on local standardized rainfall hyetographs. Thus, the aim of undertaken research was to develop unified methodology for creating extreme rainfall events, which would enable accurate representation of local precipitation dynamics. The analyses performed were also aiming at answering the question whether precipitation registered in the area of a single city shows some similarity which would be describable with the use of a simplified pattern, or a set of patterns.

\section{Methods}

\subsection{Rainfall data}

Pluviographic measurement results registered by gauges installed in two meteorological stations (A and B) in the centre of a city in northern Poland constituted research material used in this paper. The identification of characteristic rainfall scenarios began with selecting storm rainfalls from available local rainfall time series. Station A provided a compilation of rainfall volume from the years 1966-1993. The data was a series of sums of 5-minute rainfalls and was collected from all available pluviographical strips with resolution of $0.1 \mathrm{~mm}$ rainfall depth. Rainfall time series usually comprised months from April till October with temperatures above zero, when pluviograph exploitation was possible.

In case of station B, rainfall series from the years 2010-2015 were available. They were registered with the use of electronic tipping bucket rain gauges. The gauge was equipped with a heating system, which enabled precipitation registering also during winter. The 
equipment provided annual 1-minute rainfall time series with resolution of $0.2 \mathrm{~mm}$ rainfall depth.

Together from both gauges rainfall time series from 34 years were collected. They made a substantial collection of local rainfall register for the implementation of assumed method. Storm rainfalls were separated from available rainfall time series, according to standard criteria included in guideline ATV-A118P [15]. As a minimum limit of total depth of storm rainfalls $10 \mathrm{~mm}$ was adopted, and minimum time between single rainfalls was established as at least 4 hours. Moreover, for time series to be established as part of rainfall event as regards time and depth, minimum value of rainfall depth $-0.1 \mathrm{~mm}$ in 5 minutes - was assumed to separate rainfall from dry periods. As a result, 236 storm rainfalls were separated from rainfall time series, corresponding to their frequency at almost 7 rainfalls a year. Those rainfalls had depths in the range of 10.0 to $118.3 \mathrm{~mm}$ and duration from 35 to 3634 minutes.

Due to observed differences in rainfall time and depth, double normalized cumulative storm rainfall hyetographs were prepared for further analysis of separated storm rainfalls collection and for the identification of typical (meaningful, standardized) hyetographs. The duration and depth of cumulative hyetographs were normalized successively for the range from 0 to $100 \%$ for time and from 0 to 1 for rainfall depth.

\subsection{Statistical analyses}

The lack of apparent correlation between rainfall depth, as well as total time, and the shape of cumulative histogram prompted the authors to analyze the full collection of 236 rainfalls and to implement advanced data mining. The tools used were cluster analysis algorithms. The aim of cluster analysis is to divide the collection to a number of groups, characterized by certain qualities. Moreover, the groups encompass subsets of studied population, fulfilling the conditions of disjointness and completeness [16]. In this paper, cluster analysis was used to divide the set of 236 double normalized cumulative storm rainfall hyetographs into nondetermined and a priori determined number of groups. To this result, hierarchical cluster analysis and non- hierarchical cluster analysis - k-means method - was implemented accordingly. Calculations were made in Matlab.

Agglomerative methods initially assume that each element is a cluster of its own. When the methods are applied, the closest (and thus the most similar) elements are combined into new clusters, joining elements and clusters created at earlier stages, until one master cluster is created. It was necessary to define the distance between elements and created clusters, as well as the rules of linking, determining which clusters are similar enough to be combined. In the analyses the most popular and natural metrics were used: Euclidean metric and squared Euclidean distance. Euclidean metric $\mathrm{d}(\mathrm{x}, \mathrm{y})$ of elements $\mathrm{x}$ and $\mathrm{y}$ is given by formula (1) [16]:

$$
d(x, y)=\sqrt{\sum_{i=1}^{p}\left(x_{i}-y_{i}\right)^{2}}
$$

where: $x=\left(x_{1}, \ldots, x_{p}\right)$ and $y=\left(y_{1}, \ldots, y_{p}\right)$. Formula (1) for $p=2$ and $p=3$ is equivalent to distance of two points $x$ and $y$ in plane and space.

Single linkage method was used in analyzing the set of selected rainfalls. The method is also called nearest neighbour clustering, as the distance between two clusters is determined by the distance between two closest neighbours belonging to different clusters. Dendrograms illustrate the structure of a set of elements according to diminishing similarity 
between its elements (and thus increasing linking distance). In conducted research, the number of clusters was established after analyzing a dendrogram which had been made as a result of hierarchical agglomerative method. Thus, eventually not only specific storm rainfalls assigned to given clusters were obtained, but also average cumulative rainfall hyetographs. On the basis of average normalized cumulative storm rainfall hyetographs, standardized rainfall hyetographs were developed for their practical application in modelling and designing drainage systems.

\section{Results and discussion}

Fig. 1 presents, respectively, histograms of time and total depth of selected rainfalls. Cross-check shows that rainfalls of duration up to approximately $500 \mathrm{~min}$ and of depths in the range from 10 to $20 \mathrm{~mm}$ were the most common. Specific occurrences, however, differ not only in time and depth, but also in the shape of hyetographs. Therefore an attempt was made to divide the set of all standardized hyetographs with the use of cluster analysis. The result of agglomerative method applied to the set of selected rainfalls is presented in Fig 2. It is a dendrogram showing the neighbourhood (i.e. similarity of shapes) in the group of all 236 standardized hyetographs. On the basis of this hyetograph, for link length set at about 2.5 , it can be concluded that there are five different groups of rainfall clusters with similar hyetograph shapes within the cluster. Based on this, in the last stage of research consisting in grouping by $\mathrm{k}$-means method, the number of clusters was assumed at $\mathrm{k}=5$. The graphs of average cumulative storm rainfall hyetographs for 5 clusters selected by k-means method are shown in Fig. 3. For each of the clusters, its percentage in the total set of 236 storm rainfalls, as a measure of frequency with which storm rainfalls of a similar hyetograph shape take place, was determined. The analyses demonstrate that the most frequent is type 1 cluster, comprising $1 / 3$ of the whole set. Type 3 is also highly frequent (28\%). Type 5 and 2 clusters constitute a similar and much lower percentage in the whole set, amounting to only ca. $15-16 \%$. The smallest cluster is type 4 cluster (only $8 \%$ of cases).
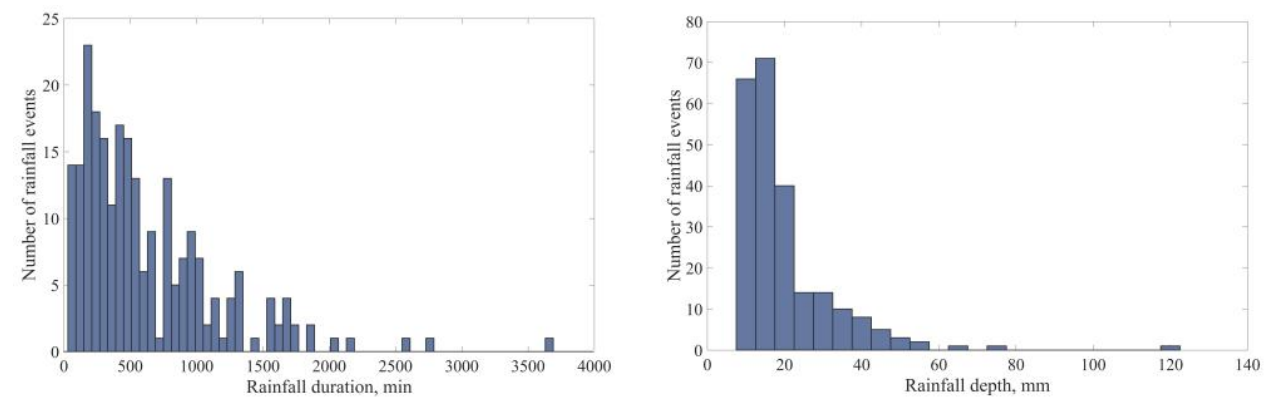

Fig. 1. Histogram of rainfall duration (left side), b) rainfall depth (right side) for a set of $236 \mathrm{storm}$ rainfalls. 


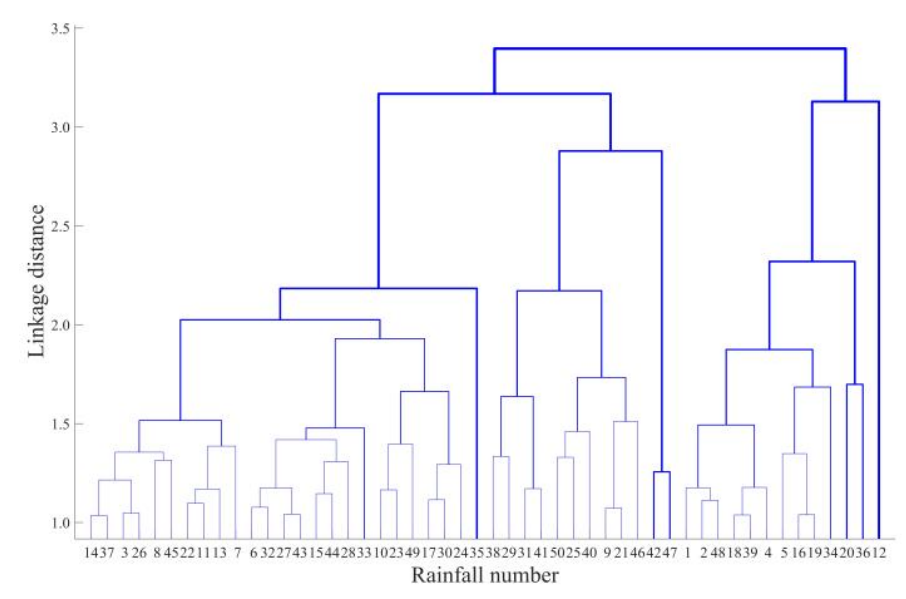

Fig. 2. The result of agglomerative analysis of selected storm rainfalls as a dendrogram (axis y shows linkage distances for individual rainfalls and rainfall groups, for better legibility some branches present hyetograph subsets.

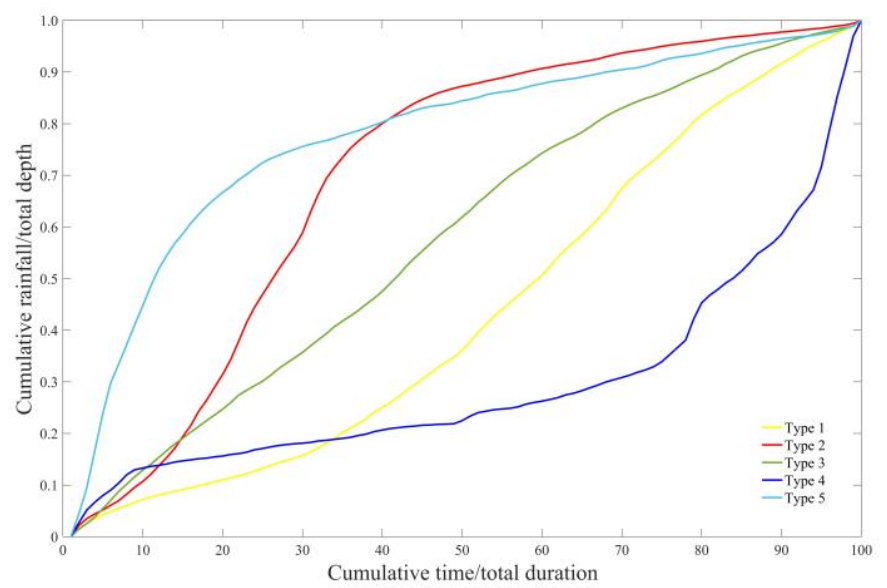

Fig. 3. Cumulative dimensionless hyetographs of storm rainfalls for 5 clusters determined with k-means method.

Presented research results prove that naturally changeable rainfalls registered in a single city area are somewhat similar, which enables to record the shape of hyetographs in time with the use of patterns. It is useful in designing which strives at generalizing (standardizing, normalizing) rainfall distribution curves. In case of the analyzed city, 5 characteristic types were separated from rainfall time series recorded in 10 years. Bearing in mind the probability philosophy in designing drainage networks, as well as limitations resulting from e.g. the costs of proposed engineering solutions, the focus must now concentrate on adjusting drainage system to the most frequent rainfall scenarios. In the analyzed case that would be model rainfall type 1, 2 and 3 (with relatively equal instant rainfall intensities), which correspond to the time series of approximately $76 \%$ of extreme rainfall events. Only afterwards the attention of an engineer may focus on modifying or rebuilding drains and system facilities (i.e. retention reservoirs, pumping stations etc.) in 
order to provide entirely proper functioning of drainage system for model rainfalls according to type 5 and type 4 hyetographs.

It is worth noticing that real rainfall hyetographs were not actually similar to the one commonly used in Poland, namely Euler's type II. As a result, in group 5 of selected model rainfalls only type 2 model was similar to Euler's type 2 . To a lesser extent the similarity was noticeable for type 5 model hyetograph. Both types ( 2 and 5 ) constituted only $15 \%$ of extreme rainfall events in the general rainfall base.

Due to the fact that selected hyetograph types differ from one another not only as regards maximum instant rainfall intensity, but also in the location of peak in hyetograph, it is recommended that future research should aim at showing the influence of hyetograph shape (type of designated pattern) on rainwater runoff simulation. The influence may be significant, as suggested in the study by Mazurkiewicz et al. [17], performed for different standardized hyetographs known from literature.

\section{Conclusions}

The hydrodynamic model may be a useful tool in hydraulic analysis of drainage systems, provided that it will be fed with rainfall data of the most resemblance to the local (real) rainfall character. A visible increase of interest in rainfall observation and processing its results for urban hydrology (with registering high resolution rainfall data) reduces the access barrier to rainfall observation time series. This means that research material for analyses with the use of the methodology presented in this paper is becoming increasingly richer. The results of complex studies performed on the set of 236 rainfalls registered in urban areas, with depths in the range from 10.0 to $118.3 \mathrm{~mm}$ and duration from 35 to 3634 minutes, enabled to formulate the following conclusions and generalizations:

1. Available registered rainfall time series should be treated as a base to build a local rainfall model. The model may later be used to create synthetic rainfall hyetographs, which have the same statistical characteristics as real rainfalls. Such compilation of data may then be used as future potential rainfall scenarios, applicable to computerized simulations.

2. In order to make the modelling of urban drainage networks more closely corresponding to real conditions, it is necessary to include at the input apparently random character of rainfalls, which is reflected in hyetograph. By using a specific method of rainfall event classification, it is possible to group rainfalls into a certain, limited number of standardized hyetograph types.

3. The classification method used in the analyses, namely cluster analysis, proved to be an effective tool to assess varied shapes of normalized hyetographs in dedicated rainfall subsets of different total duration ranges. Dendrograms achieved as a result of the analysis enable to quickly select characteristic hyetographs and identify especially atypical rainfall distributions in time.

4. Euler's type II model rainfall hyetograph was not consistent with the shape of real rainfall hyetographs. In separated types of model rainfalls it resembled type 2 model the most and to a lesser extent type 5. Both types constituted only ca. $15 \%$ of storm rainfalls in the rainfall database.

Encouraging initial results of studies in which standardized hyetographs were prepared, substituting real precipitation time series with synthetic pattern hyetographs from the local model, should be verified for other rainfall data. The data should be recorded in other cities and regions, with different local precipitation conditions. According to the authors, presented methodology is worth implementing and verifying on precipitation database from other countries, especially registered with rain gauges operating in radically different climatic conditions. 


\section{References}

1. S.S. Cipolla, M. Maglionico, I. Stojkov, Ecol. Eng. 95, 876-887 (2016) doi.org/10.1016/j.ecoleng.2016.07.009

2. P.A. Versini, D. Ramier, E. Berthier, B. de Gouvello, J. Hydrol. 524, 562-575 (2015) doi.org/10.1016/j.jhydrol.2015.03.020

3. M., Sterrena, A. Rahmana, G. Ryanb, J. Environ. Manage. 141, 1 (2014) doi.org/10.1016/j.jenvman.2014.02.013

4. E. Burszta-Adamiak, M. Mrowiec, Wat. Sci. Tech. 68, 1 (2013) doi: 10.2166/wst.2013.219

5. P. Licznar, Ochrona Środowiska, 35, 2 (2013) (in Polish) http://www.os.not.pl/docs/czasopismo/2013/2-2013.html

6. A. Kotowski, The principles of safe dimensioning of sewage systems volume I, Sewage systems (Seidel-Przywecki Publishing House, 2015) (in Polish)

7. B. Kaźmierczak, A. Kotowski, J. Hydrol. 525, 345-351 (2015) doi.org/10.1016/j.jhydrol.2015.03.063

8. P. Licznar, Gaz, Woda i Technika Sanitarna, 6 (2009) (in Polish)

9. P. Licznar, B. Szeląg, Ochrona Środowiska, 36, 3 (2014) (in Polish) http://www.os.not.pl/docs/czasopismo/2014/3-2014.html

10. A. Güntner, J. Olsson, A. Calver, B. Gannon, Hydrol. Earth Syst. Sc. 5, 2 (2001) doi:10.5194/hess-5-145-2001

11. P. Licznar, J. Łomotowski, D.E. Rupp, Atmos. Res. 99 (2011) doi.10.1016/j.atmosres.2010.12.014

12. E.A.H. El- Sayed, Ain Shams Engineering Journal, 2017 (to be published)

13. M. Barszcz, Woda-Środowisko-Obszary Wiejskie 12, 39 (2012) (in Polish)

14. B. Kaźmierczak, A. Kotowski, Verification of storm water drainage capacity in hydrodynamic modeling (Scientific papers of the Institute of Environment Protection Engineering of the Technical University of Wrocław Series of monographs No. 57, Publishing House of Wroclaw University of Technology Wrocław, 2012) (in Polish)

15. T.G. Schmitt, Kommentar zum Arbeitsblatt A 118 Hydraulische Bemessung und Nachweis von Entwässerungssystemen. DWA, Hennef (2000)

16. D.T Larose, Discovering knowledge in data. An Introduction to Data Mining (John Wiley \& Sons, Inc., Hoboken, New Jersey and Canada, 2005)

17. K. Mazurkiewicz, M. Skotnicki, M. Sowiński, Developing standardized hyetographs in simulating outflow in urban catchments (Monographs of Water Management Committee of the Polish Academy of Sciences, 39, 2016) (in Polish) 